\title{
A Highly Structured Collaborative STEAM Program: Enacting a Professional Development Framework
}

\author{
Sarah B. Bush ${ }^{\mathrm{a} 1}$,Kristin L. Cook ${ }^{\mathrm{b}}$, Robert N. Ronau ${ }^{\mathrm{c}}$, Christopher R. Rakes ${ }^{\mathrm{d}}$, Margaret J. \\ Mohr-Schroedere, Jon Saderholm ${ }^{\mathrm{f}}$ \\ ${ }^{a}$ University of Central Florida, USA; ${ }^{b}$ Bellarmine University, USA; ${ }^{c}$ National Science Foundation, USA; \\ ${ }^{d}$ University of Maryland Baltimore County, USA; ${ }^{e}$ University of Kentucky, USA; ${ }^{\circledR}$ Berea College, USA
}

\begin{abstract}
This paper reports on a highly-structured Mathematics-Science Partnership (MSP) professional development (PD) program focused on the integration of science, technology, engineering, arts, and mathematics (STEAM) in elementary mathematics and science. With a support system including higher education STEAM education and content faculty, community informal learning partners, an external evaluation team, school administrators, and expert STEAM teachers, twenty-five teachers and five STEAM instructional coaches met together for whole-group PD as they developed and then implemented integrated STEAM problem-based inquiries in their classrooms. This paper describes how the PrimeD framework (Rakes, Bush, Ronau, Mohr-Schroeder, \& Saderholm, 2017; Saderholm, Ronau, Rakes, Bush, \& Mohr-Schroeder, 2017) guided the STEAM PD program through a collaborative and reflective process. .
\end{abstract}

Keywords: Professional development, STEAM, science education, mathematics education, frameworks

\section{A Highly Structured Collaborative STEAM Program: Enacting a Professional Development Framework}

This paper presents a case study of the enactment of the Professional Development: Research, IMplementation and Evaluation (PrimeD; Rakes, Bush, Ronau, Mohr-Schroeder, \& Saderholm, 2017; Saderholm, Ronau, Rakes, Bush, \& Mohr-Schroeder, 2017), framework to guide a Science, Technology, Engineering, Arts, and Mathematics (STEAM) PD program through a collaborative and reflective process.

\section{Background}

The importance of integrating science, technology, engineering, and mathematics (STEM) is well recognized. Some proponents (e.g., U.S. Department of Education, 2015) focus on future job opportunities, noting that integrated STEM jobs (e.g., biomedical engineer) are projected to increase at more than double the rate of jobs in non-integrated STEM fields (e.g., mathematician). Others (e.g., Hom, 2014) focus on how the integration component of STEM improves the quality of learning. The addition of the " $\mathrm{A}$ " ("arts") to make "STEAM" is relatively new and recognizes the importance of the role of beauty, creativity, aesthetics, and emotion in the solution of a problem (Bailey, 2016). Peppler (2013) and Smith and Paré (2016) pointed out that 
incorporating the arts in STEM education provides a much-needed affective connection for difficult-to-grasp concepts. For students to fully realize the benefits of STEAM education, teachers need to understand both the individual disciplines and how they fit together. Cook (2016) pointed out that such preparation is not part of typical teacher PD. PD that focuses on STEAM therefore offers unique potential to improve student learning outcomes.

STEAM PD is most likely to meet its fullest potential when it is characterized by a number of elements that have been well-studied and defined. These elements are categorized in PrimeD (Rakes et al., 2017; Saderholm et al., 2017) as "elements of effective PD", that is, having an actual impact on classroom practice. Long-term PD iteratively connected to classroom practice can be challenging and complex but essential to creating real change in classrooms (Desimone, 2009; Loucks-Horsley, Stiles, Mundry, Love, \& Hewson 2010; McAleer, 2008; Sztajn, 2011). PD that has a well-planned classroom implementation component can alter teachers' practice by impacting teachers' knowledge and skills through the actual practice of teaching (e.g., Borko, 2004; Greeno, Collins, \& Resnick, 1996; Lave \& Wenger, 1991).

\section{Review of Literature on Effective Professional Development}

First, we consider effective PD broadly. Guskey (2000) and Loucks-Horsley et al. (2010) posited that the foundation of effective PD is the improvement of student learning by improving teachers' knowledge, skills, attitudes, and practices. Traditionally, teacher PD has often been conducted in ways that are disconnected from classroom practice (workshop style, as in Darling-Hammond \& Richardson, 2009) and as a result, has little long-term impact on classroom instruction. Putnam and Borko (2000) noted that teacher learning should be situated within a context. When teacher learning is "situated," the teacher is altering their practice in alignment to the PD, thus changing and growing their knowledge and skills of the teaching practice (as in Borko, 2004; Greeno et al., 1996; Lave \& Wenger, 1991). As teachers' knowledge and skills improve, they bring a different knowledge and skill level back to the PD sessions, thus improving the effectiveness of the PD itself, creating a synergistic cycle from PD sessions, through teachers' practice in the classroom, and back to PD sessions. PD conducted in this way creates a co-constructed environment in which teachers collaborate with the PD leadership team to create a learning experience that connects directly to their classroom needs and practice. This design structure creates a PD experience different from traditional PD that typically situates teachers primarily as participants, not as leaders (Timperley, 2011).

When considering more specific aspects that makes for effective PD, Borko (2004) contended there are four elements that must be examined when researching a PD program: the teacher participants in the PD program, the PD program itself, the facilitators, and the context in which the PD program and its participants function. Garet, Porter, Desimone, Birman, and Yoon (2001) identified structural (i.e. organizational) and core (i.e. substance) features of PD. Structural features consisted of the organization of activities during the PD, duration of the $\mathrm{PD}$, degree of participants' collective participation (that is, rather than teachers participating in isolation). Core features consisted of the focus of the PD; level of integrated learning; plan for classroom implementation; review of student work; opportunities for participant presenting, leading, and writing; connections to goals and between activities; communication with others; and alignment to district and/or state standards and key assessments, which also aligns to the work of Darling-Hammond (1997) and Liberman (1996). Garet et al. (2001) found PD that occurred over a longer period of time, even for multiple-years, provided more opportunities for connections to classroom practice and that longer PD fostered coherence to goals, teaching experiences, and impacted teachers' content knowledge. While Garet et al. (2001) reported a positive relationship between content knowledge and changes in teaching practice, Cohen and Hill (2000) and Kennedy (1998) noted that when PD is content specific (rather than focused on general strategies), student achievement is more likely to show improvement. 
Collective participation and coherence are two aspects of PD that are often found to be instrumental in its effectiveness (Desimone, 2009). Collective participation is the engagement of multiple participants from the same community (e.g., school, district) during the PD program (National Institute for Excellence in Teaching, 2014). Coherence addresses how well the PD program aligns with other areas of teacher participants' daily tasks, expectations, and needs. PD programs that have coherence are more likely to bridge the gap between PD and classroom practice by providing time for teacher participants to plan and receive technical support which has been found to have a strong connection to the knowledge and skills under study in the PD being implemented into the classroom (Penuel, Fishman, Yamaguchi, and Gallagher, 2007).

In summary, PD that is content-specific, aligned to clear program goals, extended over time, connected to classrooms, situated in teachers' context, and includes teachers as collaborators, co-developers and codecision-makers of the PD has the potential to be the most effective (as described in Desimone, 2009; LoucksHorsley et al., 2010; McAleer, 2008; and Sztajn, 2011). The PrimeD framework (Rakes et al., 2017; Saderholm et al., 2017) was designed to provide a structure to PD programs in a way that fosters these characteristics of effectiveness.

In this case study of enacting the PrimeD framework in a STEAM PD program, the two research questions were:

1. How was each of the four phases of PrimeD enacted in a STEAM PD program?

2. How did enacting PrimeD guide the PD providers in reflecting on the PD program across the four phases?

The sections that follow introduce, describe, and demonstrate the enactment of PrimeD in a STEAMfocused PD program.

\section{PrimeD: A PD Framework}

The work shared in this paper stems from a larger research project in which a core team of five researchers are currently working to enact PrimeD across multiple PD programs. This paper shares the journey of one of these programs, funded by a Mathematics Science Partnership (MSP) grant, Full STEAM Ahead: Preparing Elementary Teachers to Implement Best-Practices in Integrated STEAM Instruction, providing a case study in enacting PrimeD in a STEAM PD program. We specifically chose to showcase this program as all five core members of the research team were closely involved, making it ideal for describing a full enactment of PrimeD from conception to culmination.

PrimeD (Figure 1) structures PD into four phases: Design and Development (Phase I), Implementation (Phase II), Evaluation (Phase III), and Research (Phase IV). These four phases work together to guide and provide feedback to stakeholders throughout the duration of the PD program. PrimeD was designed to inform the reflective process within and between stakeholders and challenge them to explicitly consider all components of the framework throughout the duration of the PD program. We provide an overview of the four phases below. For even more in-depth information on the synthesis of literature and creation of PrimeD, see Rakes et al. (2017) and Saderholm et al. (2017). 


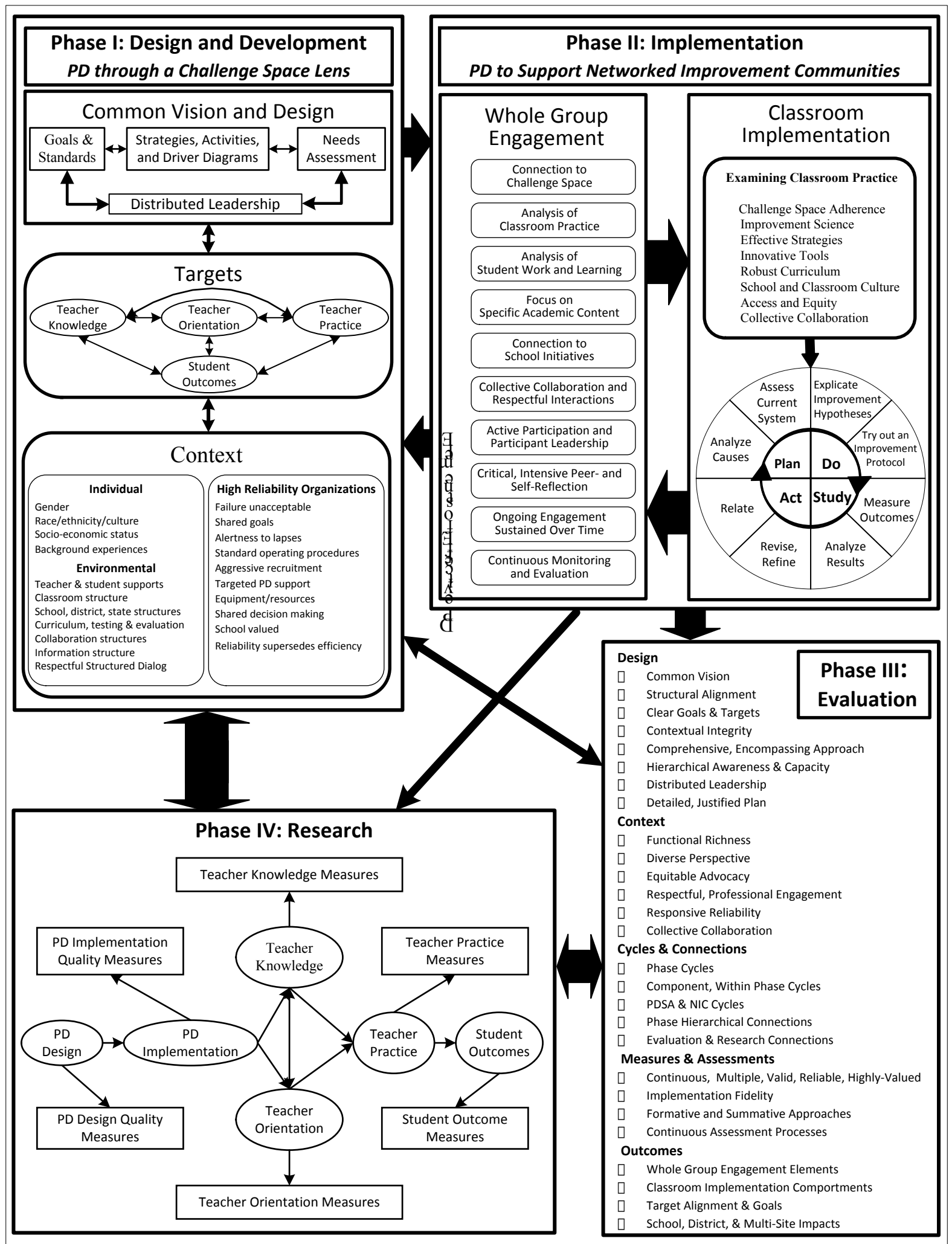

Figure 1. Professional Development: Research, IMplementation, and Evaluation framework (PrimeD; updated from Rakes et al., 2017; Saderholm et al., 2017). 
In Phase I, a challenge space (Bryk, Gomez, \& Grunow, 2010) is developed to describe a central focus, problems to be solved, target outcomes, strategies for meeting the challenges, and methods for assessing progress toward meeting the challenges. Identified strategies should consider elements of effective PD outlined in Phase II of PrimeD. Most importantly, Phase I pushes PD program providers to come together with all stakeholders involved (including teacher participants) to develop and articulate a common vision for the PD program that addresses school and classroom needs. PrimeD showcases the need for interconnectedness between common vision and design, targets, and context, as each are closely related to desired outcomes. While not intended to be exhaustive, Phase I illustrates the importance of intentionality and explicitness in determining and planning for what will or will not be addressed in the PD program. Although a single PD program may not address all components listed in PrimeD, a goal for Phase I is that whatever is not addressed is done so purposefully.

Phase II focuses on the implementation of the PD program and is divided into two components, whole group engagement and classroom implementation, with teachers intentionally engaged as partners rather than only recipients. The whole group engagement component of Phase II synthesizes key elements of effective PD (e.g., Borko, 2004; Desimone, 2009; Greeno et al., 1996; Lave \& Wenger, 1991; Loucks-Horsley et al., 2010; McAleer, 2008; Penuel, Fishman, Yamaguchi, \& Gallagher, 2007; Putnam \& Borko, 2000; Sztajn, 2011; Timperley, 2011). Providing a specific example, Desimone (2009), Loucks-Horsley et al. (2010), McAleer (2008), and Sztajn (2011) all defined elements of effective PD as (a) directly and explicitly connected with identified student learning needs; (b) intensive, sustained, and directly connected to practice; (c) specific content focused; (d) aligned to current school initiatives; (e) providing opportunities for teachers to collaborate with one another and build productive working relationships; and (f) continuously evaluated. In addition to whole group engagement, where teachers and other participants (such as instructional coaches or administrators) attend PD sessions, Phase II highlights classroom implementation of practices and strategies from the whole group engagement sessions as an equally important component of PD implementation, providing meaningful opportunities for teachers to develop, practice, and reflect on their practice in their natural teaching environment (as recommended by Philippou et al., 2015; Steyn, 2015; Timperley, 2011). To structure the classroom implementation component, teachers use Plan-Do-Study-Act (PDSA) cycles (Bryk et al., 2010; Martin \& Gobstein, 2015) to carry out trials of change ideas in their classrooms. Using PDSA cycles empowers teachers as researchers of their own classrooms. Over time, the implementation and refinement of a series of PDSA cycles become a results-driven innovation engine not only for that individual teacher, but for others in the PD program. This connection of whole group engagement to classroom implementation has been consistently shown as critical for connections between the PD sessions and participants' ongoing classroom practice to be realized (e.g., Hiebert \& Stigler, 2000; Hiebert et al., 2005; Jones \& O’Brien, 2014; Philippou et al., 2015; Sabah, Fayez, Alshamrani, \& Mansour, 2014; Timperley, 2011). As participants enact PDSA cycles, they return to the whole group engagement PD sessions and engage in reflecting, troubleshooting, and planning with fellow participants. Collaborative activities such as peer observations and analysis of student work samples are used to improve teacher practice and subsequently, student achievement (as advocated for in Darling-Hammond \& Richardson, 2009).

Phase III is dedicated to the evaluation of Phases I and II both formatively and summatively. Ideally, iterative evaluation throughout Phases I and II should provide formative support to PD program providers in addition to the more commonly practiced summative evaluation. Evaluation of Phase I should examine the degree of comprehensiveness and clarity of the challenge space as well as how the challenge space is understood and applied by all stakeholders throughout the PD program. Another key tenet is that PD design should be considered dynamic and can and should be adjusted along the way according to evaluation results. For example, when difficulties and obstacles arise, evaluation can objectively examine how they were used to refine the goals, targets, and strategies or to better understand nuances within the challenge space. Evaluation of Phase II should focus on how well the whole group engagement consistently includes the identified elements of effective PD and the extent to which classroom implementation is connected to whole group engagement. Before evaluation leads to changes in Phase II, PD providers should first consider how potential changes are related to the challenge space (i.e., one-way arrow from Phase II to III in Figure 1). By making design changes 
through Phase I and involving all stakeholders, including participants, in such decisions, modifications can become systemic and will filter to Phase II with a higher level of stakeholder support and influence greater fidelity as everyone is on the same page.

Phase IV (research) is interrelated yet distinct from Phase III (evaluation), as noted by Chyung (2015). Both evaluation and research involve investigation and inquiry, similar methods, and some of the same data sources. However, evaluation is generally context-specific whereas research tends to seek generalizability (Chyung, 2015). More specifically, evaluation questions examine how well program outcomes are met whereas research questions examine possible factors that may have influenced why outcomes were reached or not reached. For example, evaluation of Phase II might address how well whole group engagement included the elements of effective PD while research might instead investigate which of those elements had the greatest potential for impacting classroom practice.

PD programs that address the effective elements of PD described above are complex and difficult, therefore, a conceptual framework, such as PrimeD, is needed to guide PD providers' process of designing and developing, implementing, evaluating, and researching the effectiveness of their PD programs in efforts to guide widespread and systematic improvement in the perception and effectiveness of PD (Rakes et al., 2017; Saderholm et al., 2017).

\section{Methodology}

The methodology used for this study was a single case study (Yin, 2017), where enacting PrimeD in one in-service PD program was considered the case. Because a case study examines data sources in an effort to support or refute propositions (or theories) to advance those ideas, we identified initial propositions from PrimeD. We then examined our data with those ideas in mind.

\section{Description of the Case}

Our integrated STEAM PD program drew on two reform models: problem-based inquiry, shown to increase urban and minority students' achievement and engagement in mathematics and science (Buck, Cook, Quigley, Eastwood, \& Lucas, 2009); and interdisciplinary learning, also shown to enhance learning outcomes and engagement in mathematics and science (Czerniek, 2007). Our partner school district was a large urban district in the Midwest classified as a "Needs Improvement/Progressing" district with a state-level percentile rank of 51. The district ranked below the state average in grades K-5 mathematics and science achievement (based on the state standardized assessment). Working with district leadership, we identified five elementary schools to participate in the PD program, one of which was a new school. Each of the five elementary schools were in the beginning stages of conceptualizing STEM/STEAM initiatives as a strategy for increasing science and mathematics achievement. After the five schools were identified, principals and district leadership recruited grades 3-5 teachers at each school. Additionally, one instructional coach or STEM/STEAM lab teacher at each school was recruited as the STEAM coach for that school. Therefore, each of the five schools had one STEAM coach and a group of teachers (between 2 and 9 depending on the school) as participants. While the PD program focused on grades 3-5, one second grade teacher and one special education teacher participated at request of the district leadership. Program participants were 25 classroom teachers and 5 STEAM instructional coaches. Teachers' classroom teaching experience ranged from two to more than 20 years. Their educational attainment ranged from a bachelor's degree to multiple graduate degrees primarily in education (not in the content areas of mathematics or science). No teacher or STEAM instructional coach participant held a terminal degree.

Key stakeholders in the PD program included local non-profit informal learning education partners, the building administrators from the five schools and district administrators, an expert STEM lab teacher, an expert STEAM lab teacher, a STEM center founder who served as a consultant, and higher education faculty 
in science, mathematics, and education. The PD program spanned two academic years (October through April each year) with bi-monthly whole group engagement PD sessions, ongoing school-level Professional Learning Communities (PLCs), and ongoing classroom implementation. Overall, teachers attended approximately 30 whole group PD sessions over the two academic years, some occurring during the school day from 8:30 a.m. -3:30 p.m. and others in the evening from 5:00 p.m. - 8:30 p.m., for a total of 130 hours of PD. The PD program also included nine hours of initial training for the STEAM coach at each school as they were responsible for leading the STEAM PLC for participating teachers in their building. Peer observation and feedback were built into the core structure of the PD program. At the end of each year, STEAM coaches and teachers (and some of their students) from the five participating schools as well as our informal learning partners hosted a free public community "Maker" event. PD program goals included 1) increase students' science and mathematics achievement; 2) increase teachers' and coaches' mathematics and science pedagogical content knowledge; and 3) build a community of educators dedicated to integrated STEAM teaching and learning.

\section{Data Collection and Analysis}

Throughout the two-year duration of the PD program, data were amassed that included teacher-level, student-level, and administrator-level data specific to the three project goals described above. For purposes of this single case analysis, multiple sources of qualitative data (Creswell, 2009) were most relevant to the research questions. These data included videos of whole group PD sessions, document analysis of artifacts including STEAM inquiry planning documents, teacher lesson reflections, student work samples, emails between facilitators and instructional coaches and facilitators and the external evaluation team, iterative qualitative feedback from external evaluators, and unstructured individual and group conversations. These documents were triangulated to inform the data analysis for this study.

To guide the data analysis, a priori propositions under study came directly from components in PrimeD including 1) common vision and design, 2) targets, 3) context, 4) whole group engagement, 5) classroom implementation, 6) evaluation, and 7) research. These propositions enabled us to determine ways in which using the PrimeD framework guided us as PD providers or fell short. As a research team (PD providers and external evaluators), we conducted a SWOT (strengths, weaknesses, opportunities, threats) analysis for each proposition. For each of our seven propositions, data were triangulated to gain a holistic sense of how PrimeD helped (or did not help) navigate a specific component of the PD. Major themes and patterns emerged from the triangulation of data for each proposition. For example, with regard to the critical and intensive peer and self-reflection component of whole group engagement, we triangulated the following data: the PD providers' in-the-moment noticings, external evaluation team meeting notes, observation instruments completed by the external evaluation team, and document analysis of reflections by teachers. This revealed that the critical and intensive peer and self-reflection component was underdeveloped. We were also attentive to external factors that may have influenced each proposition beyond PrimeD, such as other demands placed on teachers by the district, conflicting school initiatives and testing pressure, and teacher preconceptions and buy-in regarding the PD program.

Several methods were used to enhance the trustworthiness of the findings. The triangulation of qualitative data sources required themes to be the result of multiple forms of evidence (Patton, 2002). The external evaluation team provided peer debriefing throughout the PD program through written feedback and acting as a sounding board for ideas as recommended by Creswell and Miller (2000). Every PD session was analyzed by the facilitators and the external evaluation team for emergent themes (i.e., prolonged engagement; Lincoln \& Guba, 1985) and to provide feedback on implementation of PrimeD (i.e., persistent observation; Lincoln \& Guba, 1985). 


\section{Results}

This case study examined the enactment of PrimeD in a STEAM PD program. The two research questions prompted an examination of how all four phases of PrimeD were enacted in the STEAM PD and how that enactment guided the PD. Results are structured by examining each research question for each phase of PrimeD.

\section{Phase I: Design and Development}

Research question 1. Our design and development work began approximately six months prior to the start of the PD program through initial conversations with the mathematics and science district specialists at our partner school district. In collaboration with these district content specialists, we developed a vision that met the needs of the district and teachers, was grounded in research-based best practices in both PD effectiveness as well as teacher pedagogy and content development in mathematics and science education, and which were aligned to our three project goals (see description of case above). By learning about and understanding the governance structures of the district, we were able to determine the best methods for communicating with district and building administration, STEAM instructional coaches and teachers, and the district research and evaluation team.

Our PD program focused on mathematics and science taught in grades three to five as outlined in the Common Core State Standards for Mathematics (CCSSM; NGA Center for Best Practices \& CCSSO, 2010) and Next Generation Science Standards (NGSS Lead States, 2013) content and practices. The district's research and evaluation team provided summary data from district quarterly assessments. Each of the items in the quarterly assessment were aligned to clusters of grade-level CCSSM content standards. For our participating schools, we were able to identify the clusters in which students struggled the most. This information served as part of our program needs assessment and helped us tailor the PD to areas needing the most support. We aligned these identified mathematics achievement gaps to science content and practices to ensure we were also addressing students' science learning and achievement. Through this collaboration, we decided to measure student achievement through both the state standardized assessment as well as district quarterly assessments called "proficiencies."

Each participating school was selected because they were in the beginning stages of conceptualizing school-wide STEM or STEAM programs as an avenue to increase mathematics and science achievement. With the use of one STEAM coach in each of the five schools to lead school-level STEAM PLCs and to help facilitate the classroom implementation portion of the PD, our program was strategically designed to build schoollevel capacity in terms of teacher leadership, infrastructure, and materials/resources. Teacher support included close partnerships with community stakeholders (e.g., a local state science center, center for performing arts, and an art museum), direct involvement by school and district administrators, a STEM center founder who served as a consultant, an external evaluator who specialized in mathematics education and research design (and his team), an expert K-5 STEM lab teacher with over 20 years teaching experience who is also a national Engineering is Elementary PD facilitator, an expert K-5 STEAM lab teacher with over 10 years teaching experience who has received multiple teaching awards and recognitions, and two higher education faculty in science and mathematics to serve as content experts. The key investigators, who were also the lead facilitators on the project, were a mathematics teacher educator and science teacher educator interested in the effectiveness of integrated STEAM instruction.

The STEAM coaches and district content specialists were instrumental in ensuring the PD program was tightly connected to district demands (i.e., curriculum maps, standards, and assessments), centered on the needs of local students (i.e., interests and available supports), and aligned to related initiatives in the district (i.e., district-developed curricula and existing resources). An unexpected outcome of this close partnership was the impact on a district-level content coach. Because of their experience with PrimeD, this coach made changes to district PD by explicitly including an interdisciplinary content focus rather than only a pedagogical focus 
as had been done in the past. Reciprocally, this same coach has helped us understand the organization of the district science curriculum maps and the constraints and schedule by which the teachers must adhere. Working collaboratively with school district leadership in year two of the project uniquely helped to prepare participants as our state released a completely revamped science standardized assessment. This assessment occurred during year two of our PD program and we adapted program PD plans to meet this timely need for our participants. Also, in year two, district specialists were more involved in our whole group engagement PD sessions, and having their expertise as well as a district lens to statewide assessments served as a great asset.

Research question 2. We found that being transparent and explicit about our vision and program decisions was a key strategy to support collaborative and reflective efforts in Phase I. We shared and discussed the PrimeD framework with our STEAM coaches, partners, and leadership team, and subsequently with teachers. Figure 2 showcases sample handwritten notes aligned to Phase I used to focus our conversations. We found it extremely helpful to have the STEAM instructional coaches as a key part of these conversations in part because district leaders had the opportunity to share a dialogue about the program. For example, at one such meeting, a district-level administrator stated that:

This project aligns to the focus on STEAM that was evident at a federal Title II conference I recently attended in DC. This work is valued nationally and is positioning us as innovative leaders in STEAM. Your (the coaches) collaborative leadership will guide us in sustaining this project long-term. (District Leader, MSP Meeting, 2016)

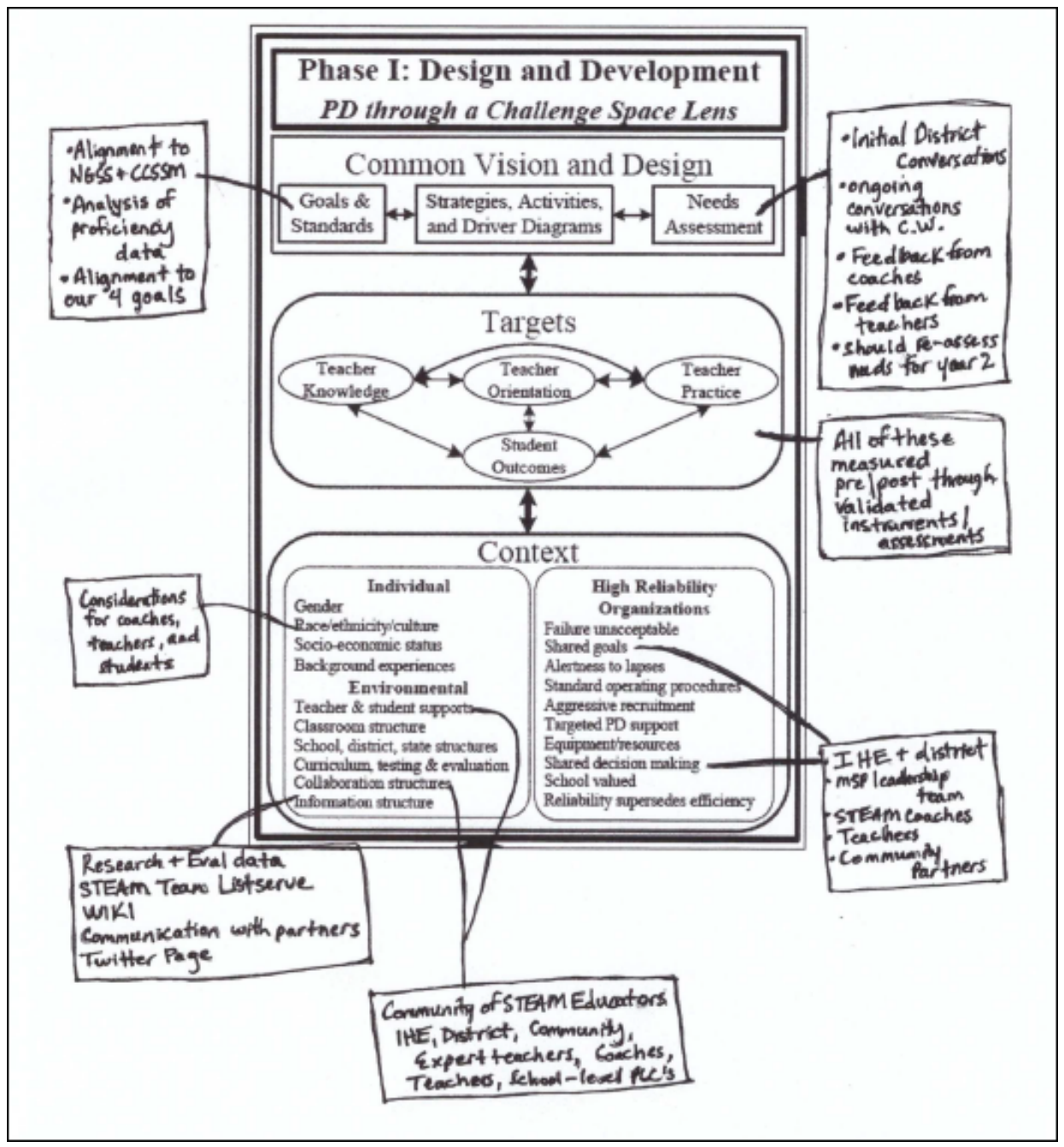

Figure 2. Phase I notes 
The PrimeD framework served as a springboard to launch and manage difficult conversations about areas of concern. For example, we needed stronger communication with building principals. Explicitly holding ourselves accountable for Phase I led us to brainstorm with our external evaluator, which resulted in the addition of a monthly newsletter we began sending to building and district leadership so they could keep abreast of the innovative work of their teachers, STEAM instructional coaches, and their students. This newsletter proved to be an invaluable tool for communication and we received immediate positive responses from several building administrators.

Phase I also helped us think critically about the constructs we planned to measure (e.g., teacher knowledge, teacher orientation, teacher practices, and student outcomes). Although we had an agreement with the district regarding which student achievement measures would be collected, a misunderstanding at some schools put us at risk of missing student data. Structuring the conversation around PrimeD helped us facilitate a potentially acrimonious interaction regarding the need for the student measures to assess the quality of the $\mathrm{PD}$. As a result of structured conversation aligned with the PrimeD challenge space, we were able to positively manage the situation and obtain the needed data.

Finally, as we have learned to understand and enact PrimeD more effectively, an important lesson with regards to Phase I was realized. During our initial planning time, six months prior to the official start of the PD program, only K-12 district-level mathematics and science specialists were primarily involved in collaborating with us on identifying program goals, key content to be addressed, and the general structure of the PD. It was not district protocol to invite STEAM instructional coaches and teachers (the future participants) into the initial planning process (prior to the beginning of whole group engagement PD sessions). In hindsight, doing so would have provided a different and needed viewpoint. While the STEAM instructional coaches and teachers played a large role in our planning discussions in the latter half of year one and year two, next time, we now know to advocate for their initial inclusion because such collaboration from the start would have created a more united feeling amongst the entire group. This finding aligns to the work of Jones and O'Brien (2014) who observed that PD organized from the top down (in this case, planning coming from the district level) creates a rift between the policy decision making and teachers having a voice in identifying their own PD needs. As advocated for by Philippou et al. (2015), teachers should be involved in the initial design so the PD program is best aligned with their individual schools and classrooms.

\section{Phase II: Implementation}

Research question 1. The PrimeD framework helped us make explicit and deliberate decisions regarding how the PD program would be structured (i.e., intense, on-going, connected to practice, focus on academic content, and collaborative). Moving back and forth between whole group engagement and classroom implementation is inherently complicated and challenging but is critical for situated learning (e.g., Lave \& Wenger, 1991) and teacher reflection. To best connect the experience to classroom practice, the PD program took place during the academic year, from October to April. We met with teachers after school approximately twice a month and during all-day meetings four times each year.

In Phase I, we originally planned for STEAM instructional coaches from each school to organize the classroom implementation portion as well as conduct follow-up meetings with teachers to facilitate discussion and reflection. This expectation proved challenging and unrealistic because we found that the five schools were each structured quite differently. For example, some participating schools had a STEAM lab, others co-taught STEAM in their various classes, while others departmentalize to teach different components of a singular STEAM inquiry. PrimeD provided us with a research-based resource to support requests that were demanding on schools. For example, we discovered that teachers had little or no time at their schools to meet as a STEAM PLC. Consequently, we approached administrators about providing time for the STEAM PLCs to convene during the school day. We also allocated more time during our whole group engagement PD sessions to facilitate PLC work centered on reflection and analysis of student artifacts. Figure 3 showcases sample handwritten notes aligned to PrimeD Phase II used at a leadership meeting to emphasize the importance of the 
multiple components of this phase.

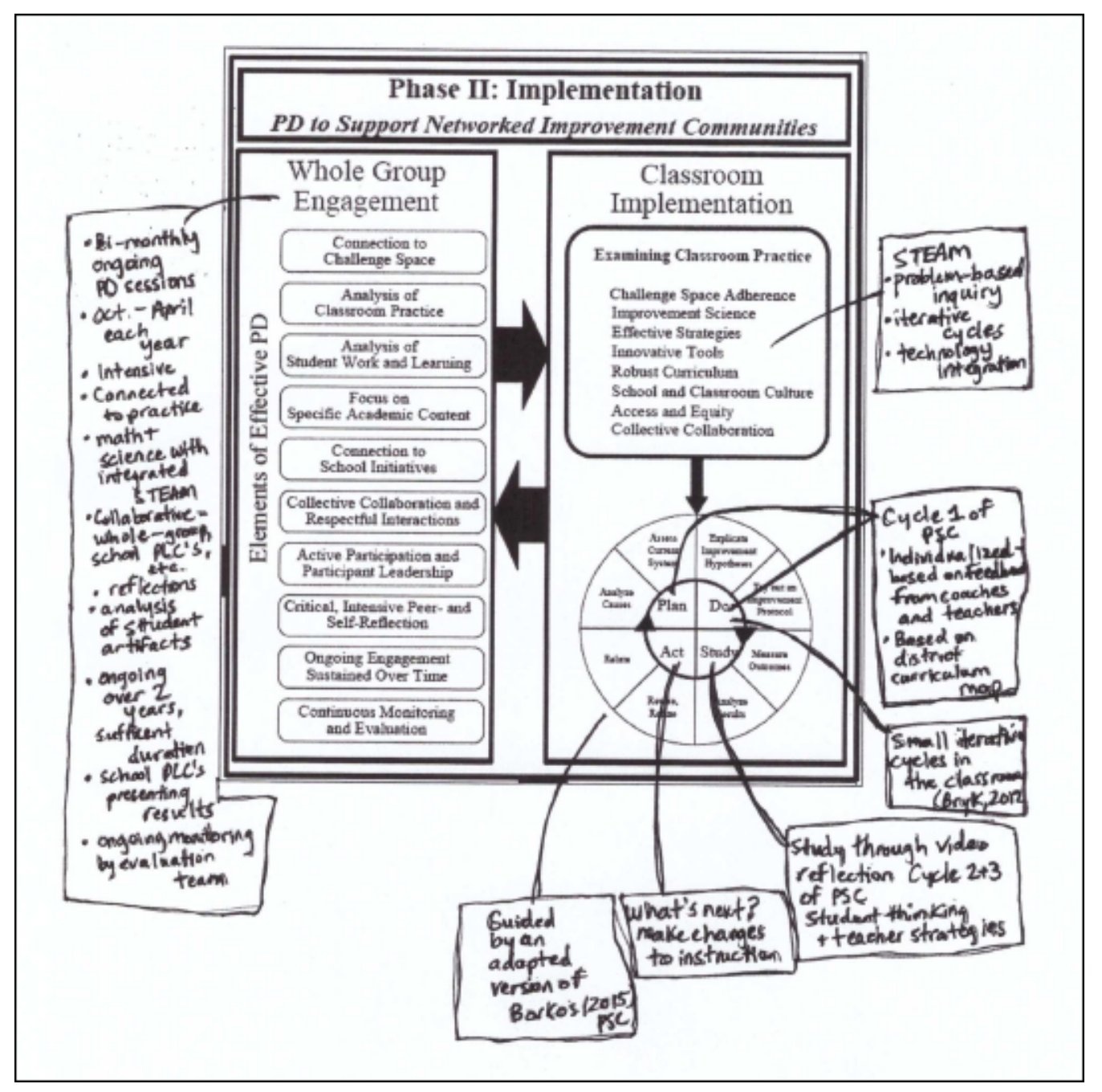

Figure 3. Phase II notes.

An adapted version of the Problem Solving Cycle (PSC; Borko, Jacobs, Koellner, \& Swackhamer, 2015), through which we tackled the "Plan, Do, Study, Act" portion of Phase II, enabled us to support teachers' reflection of their content development and classroom implementation, essentially conducting action research. Specific prompts, used repeatedly and consistently during each PSC, centered on students' thinking and teachers' instructional moves. Because teachers undergo multiple rounds of the PSC throughout the PD program, this process has become more refined over time. Reflections target specific prompts about the mathematics and science content and practices as well as the integrated nature of the instruction. Teachers adjusted their inquiries to prepare for richer discussions with students. Teachers became more reflective on their own instructional techniques as they aimed to maximize students' mathematics and science content and practice development.

Research question 2. Collaborative reflection among the leadership team, coaches, and teachers after the first PSC revealed that teachers were attempting to emphasize too much content in their STEAM inquiries-often with the result of addressing content too broadly at the expense of depth. Therefore, during the next round of the PSC, we asked teachers to limit the content emphasis to one or two standards for each of the STEAM disciplines. For example, we encouraged teachers to avoid listing all mathematics content standards that might connect to the inquiry and select only the mathematics standard(s) most closely connected and explicitly assessed. Figure 4 showcases a comparison of one PLC's first planning document, which was more 
general and broad in nature, to their second planning document, which was much more specific with regards to both standards and description of students doing the mathematics and science. The collaborative reflection process promoted by PrimeD provided a structure that guided our work helping teachers articulate welldefined expectations for their inquiries and develop clear assessments that set explicit parameters and standards alignment for their STEAM explorations.

\begin{tabular}{|c|c|c|c|c|c|}
\hline \multicolumn{3}{|c|}{ First Planning Document } & \multicolumn{3}{|c|}{ Second Planning Document } \\
\hline Content & Standard & Description & Content & Standard & Description \\
\hline Science & $\begin{array}{l}\text { PS3.B, } \\
\text { ESS3.A, } \\
\text { PS3.C, } \\
\text { PS3.D, } \\
\text { PS4.C }\end{array}$ & $\begin{array}{l}\text { Design and create either a } \\
\text { compass or a generator } \\
\text { using the lnowledge you } \\
\text { have leamed about } \\
\text { magnets and electricity. }\end{array}$ & Science & $\begin{array}{l}\text { Performance Expectation: } \\
\text { 4.PS4.3 Generate and } \\
\text { compare multiple solutions } \\
\text { that use patterns to transfer } \\
\text { information. } \\
\text { Disciplinary Core Ideas: } \\
\text { 4.PS4.A Waves of the same } \\
\text { type can differ in amplitude } \\
\text { (height of the wave) and } \\
\text { wavelength (spacing } \\
\text { between wave and peaks). } \\
\text { Cross Cutting Concepts: } \\
\text { Patterns: } \\
\text { (4.PS4.1) Similarities and } \\
\text { differences in patterns can } \\
\text { be used to sort and classify } \\
\text { natural phenomena } \\
\text { (4.PS4.3) Similarities and } \\
\text { differences in pattems can } \\
\text { be used to sort and classify } \\
\text { designed products. }\end{array}$ & $\begin{array}{l}\text { Students will create a } \\
\text { pattern using pattem blocks, } \\
\text { shapes, or letters after } \\
\text { viewing a Prezi or } \\
\text { cryptology. } \\
\text { Students will experiment } \\
\text { with the energy of sound } \\
\text { waves to move various } \\
\text { objects. } \\
\text { Students will demonstrate } \\
\text { wave lengths and amplitude } \\
\text { using ropes. } \\
\text { Students will create a } \\
\text { pattern (secret code) to } \\
\text { communicate with a partner } \\
\text { using their acquired } \\
\text { knowledge from spy cam. }\end{array}$ \\
\hline Math & $\begin{array}{l}\text { 4.MD. } 2, \\
4 . \mathrm{MD} \cdot 6\end{array}$ & $\begin{array}{l}\text { Solving word problems } \\
\text { involving intervals of time, } \\
\text { measuring angles using a } \\
\text { protractor. }\end{array}$ & Math & $\begin{array}{l}\text { Content Standards: } \\
\text { (4.NF.4) Apply and extend } \\
\text { previous understandings of } \\
\text { multiplication to multiply a } \\
\text { fraction by a whole number. } \\
\text { (4.NF.5) Understand } \\
\text { decimal notation for } \\
\text { fractions and compare } \\
\text { decimal fractions. } \\
\text { Practice Standards: } \\
\text { (SMP 5): Use appropriate } \\
\text { tools strategically. } \\
\text { (SMP 6): Attend to } \\
\text { precision }\end{array}$ & $\begin{array}{l}\text { Students will determine the } \\
\text { number of inches of wire } \\
\text { needed to construct a } \\
\text { working circuit when } \\
\text { measuring } \frac{1}{4} \text { inch units. } \\
\text { Students will determine/use } \\
\text { the appropriate operation to } \\
\text { acquire materials within a } \\
\text { given budget. } \\
\text { Students will use a ruler to } \\
\text { measure lengths of wire to } \\
\text { the nearest } \frac{1}{4} \text { inch. }\end{array}$ \\
\hline
\end{tabular}

Figure 4. Planning documents become more refined

As teachers engaged in the classroom implementation portion of Phase II, they were highly reflective about their practice, leading to many insights. Figure 5 showcases a teacher's reflection of her students' thinking as they considered the pattern between one's height and one's length of stride during a problem-based inquiry in which students determined the number of steps it would take to walk a mile. Figure 6 highlights another teacher's in-the-moment reflection of students struggling to measure to the nearest $1 / 4$ inch and as a result the PLC decided to conduct a mini-lesson on length measurement. 


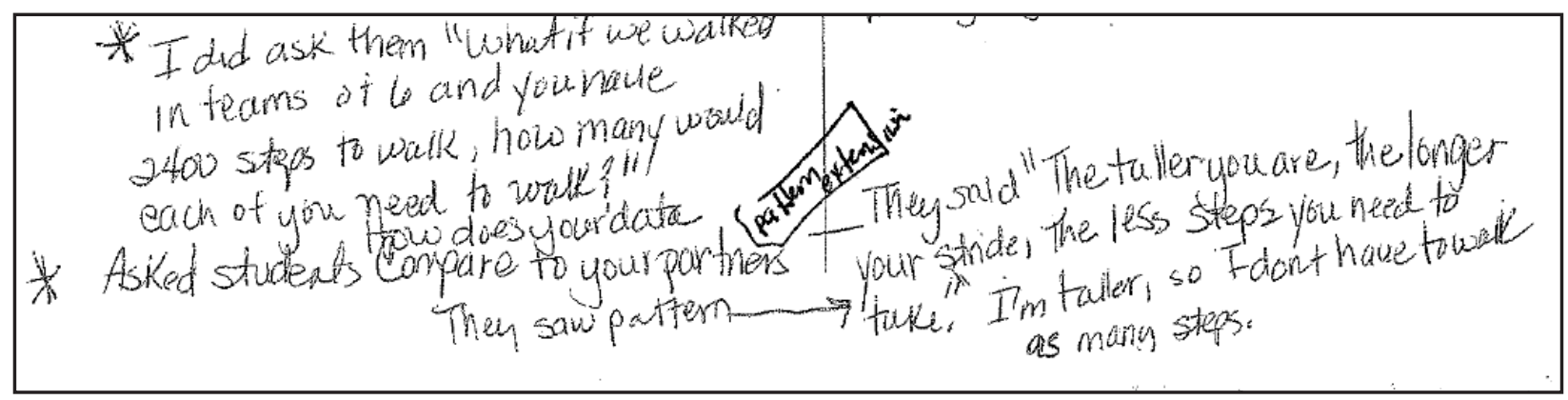

Figure 5. Teacher reflects on student generalizations on stride length.

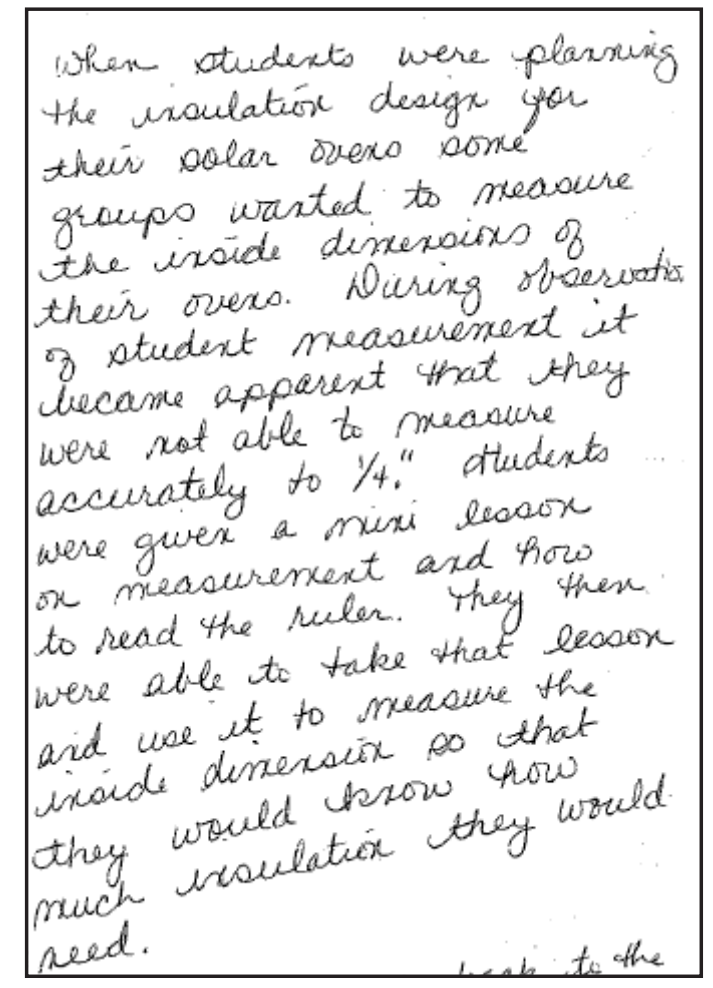

Figure 6. Teacher decides to revisit fractional length measurement as students wrestle with this concept.

Individual and small group reflections were shared with the entire STEAM community during whole group engagement PD sessions. These peer-debriefings were integral to the reflective process, as teachers are asked to share their reflections on students' thinking and their own instructional moves within the context of a PSC, as well as in terms of their growth over the course of the program. Figure 7 captures dialogue on teachers' reflective nature regarding their use of questioning near the end of the first year. For example, Mary explains how the PD program has encouraged her to use probing questions to get at deep student thinking rather than to get to the correct answer. Similarly, Maria points to how STEAM teaching has helped her place more emphasis on appropriate content vocabulary. Moreover, Carrie explains that she now capitalizes on discussion of student misconceptions. 
Facilitator: How has your use of questioning been challenged and changed throughout our year together? Has STEAM teaching necessitated a change in your use of questioning?

Mary: For me it has, being a new teacher, compared to how I was taught just to look for the right answer. As a first year teacher and seeing things you guys (points to other teachers) have done ... I used to be like 'get the right answer and move on', but now I'm like 'so tell me why, explain that, write it down, can you show me?' So for me, it has (changed my use of questioning).

Maria: I make students use the correct vocabulary now, whereas in the past if they could just kind of explain it, I was like 'Okay, I get what you are saying.' But now I say ' I get what you are saying doesn't cut it, you have to be able to formally explain it and use the correct vocabulary.'

Annie: Something that we have worked on this year that is embedded in our STEAM teaching is that now students have to come up with the questions. It takes away from my standing up there and saying 'why do you think this happened' to their asking each other questions and engaging each other. ...now it's to the point where I'm not even in the conversation. They are asking questions and having dialogue back and forth - you don't even know I'm in the room.

Jane: I think that STEAM has made my questioning more intentional and directed to students' thinking and I am more conscious of that now.

Carrie: This project has opened my eyes to having children with misconceptions explain their misconceptions and talk about it more whereas before I'd be like 'Oh, you're wrong' and I would only have the person who was correct explain.

Elizabeth: We do it in math where we say 'try to convince' and I'll play both sides of the card, and get both students to argue like we are in a courtroom. Prove your side, and I just try to stay as neutral as possible and see if anyone can be swayed and if we can come to an actual conclusion after we hear all of the arguments in the room.

Tandrea: What I've noticed in my science lab is students are having more discourse and questioning themselves and seeing that kids are taking ownership of what they understand and what they know. They even ask what is that vocabulary that we are actually talking about.

Sherry: Now I understand that if I ask a question we don't always have to answer it that class period. We can wait to tomorrow, we can let them think about it. I've always been one to say 'Okay let's get to the answer, I can't wait to tell you' but now I sit back and let them ask themselves and try to figure it out and even when they get frustrated I know that wait time is really important.

Tonya: In my world (special education teacher) it has leveled the playing field for students who come to me for half of the day. No longer does it appear that it (instruction) is different or specialized to them even though it is because I'm probing deeper for their thoughts but it's the same type of questioning for the kid sitting next to them. It's leveling the discussion.

Figure 7. Teacher reflective dialogue on questioning.

As we reflected on enacting Phase II of PrimeD to guide our STEAM PD whole group engagement and implementation, we shared in this section several key results regarding how PrimeD helped guide our thinking and decision making. Not all of Phase II can happen at once, but by using Phase II (and cycling back to Phase I), we were able to intentionally decide how and where to place our focus during year one. For year two, the focus of our whole group engagement shifted to Active Participant and Participant Leadership and Ongoing Engagement Sustained Over Time as we knew the importance of building capacity in each school so the impact of our program would extend beyond the scope of our funding. Our implementation focus shifted to teachers 
observing each other's classrooms.

\section{Phase III: Evaluation}

Research question 1. The observations of the PD program by the external evaluators were limited primarily to the whole group engagement sessions in Phase II (as well as attending selected leadership team meetings). Because PD sessions were conducted throughout the academic year, we were able to infer connections from the whole group engagement sessions to Phase I and to classroom implementation; that is, the degree to which classroom implementation artifacts drove the whole group engagement sessions during the academic years. We videotaped the whole group engagement PD sessions so that the external evaluators could review and complete an observation instrument. The lead evaluator coded some PD sessions on-site. The evaluation team used an observation instrument adapted from Horizon Research (2000) to rate the PD sessions during year one; however, ratings were at the top of the scale ( 4 or 5 in a 1-5 scale) for all four evaluators (i.e., restricted range threat to validity as in Shadish, Cook, \& Campbell, 2002). The evaluators concluded that the Horizon instrument was developed for traditional PD, and the use of the PrimeD framework propelled the present PD program to a higher overall rating. For example, the instrument included ratings for PD culture, which included items such as "active participation of all was encouraged and valued." In traditional PD, participants are often situated as recipients of new information whereas the PrimeD framework explicitly calls for participant leadership during whole group engagement and classroom implementation. The instrument rates the frequency of indicators occurring from "Not at all" to "To a great extent." By such a rating scale, the present PD program consistently met this criterion to a great extent as rated by the PD program evaluation team. Having achieved such a benchmark, the evaluation team focused on rating the quality of the active participation, not just the frequency. In the absence of a reliable, valid instrument to rate such quality across all indicators, the team focused on providing qualitative feedback to the PD providers.

Using the PrimeD framework and the three program goals as guides, the evaluators were able to make a number of formative recommendations to the PD providers that fell into the following categories: strength of the connections to the challenge space (vision, goals, outcomes and context) and to classroom implementation, communication and networking within and among participant schools, explicit focus on content and practice standards in each PD session and in teacher-developed STEAM inquiries, sharing of leadership, responsibilities and information with PD participants, and solving problems with participants and partners.

Research question 2. The PD providers found feedback from the external evaluation team to be one of the most crucial aspects for improving their program. For example, we were challenged to place a more explicit emphasis on the mathematics and science practices, an area that needed work. We also learned we needed to ensure tighter articulation of the STEAM inquiries with the district's diagnostic and proficiency assessments. We found that PrimeD provided a structure so that the evaluation was not an add-on component but an integral part of the overall process. More than challenging us to make our measures and data collection more explicit, the evaluators helped us better understand, connect, and improve the multiple feedback cycles essential to providing an optimal PD experience for teachers. For example, we discussed with the whole group of participants how results from PD implementation informed the challenge space, and we deliberated on which specific information from the classroom implementation experience was needed to provide critical feedback to the school-level PLCs and at the same time serve as a learning experience for the whole group. The evaluation phase helped us extend the improvement cycle as an engine of change in the implementation phase to one that drives all phases of the PD program.

Phase IV: Research

Research question 1. In the current program, both internal and external evaluation focused on improving various aspects of the PD program. The research, on the other hand, focused on how PrimeD influenced the ability of participants to meet the target outcomes. For example, we researched participants' progress through enactment of PDSA cycles, analyzing the critical connection between whole group engagement sessions and classroom implementation. In year two, we piloted a classroom observation tool for participants to provide 
feedback to each other. We examined the extent to which providing this type of feedback informs and changes the observer's own classroom practice. We also examined the degree to which teachers' use of PDSA cycles improved the quality of the whole group engagement PD sessions.

Research question 2. By recognizing evaluation and research as two distinct yet interconnected phases of PrimeD and our PD program, we have distinguished what needs to be reported to conduct the evaluation to determine the effectiveness of the program while extending far beyond that to think about the deep research we wish to explore. Upon reflection, PrimeD has guided and encouraged us to explore questions beyond what we might have had we been explicitly focused on the evaluation rather than both.

\section{Discussion}

The goal of the PD in this case study was to advance teachers' ability to integrate STEAM into their classroom instruction. The use of PrimeD to structure the PD helped reach this goal. While the specific goal of this PD was unique to the integrated STEAM field, the PD program was similar to PD broadly in that it had a general goal of helping teachers improve their professional practice. We therefore assert that the benefits of PrimeD seen in this case study are transferable to PD in general. In this section, we highlight key implications this research has on teachers and PD providers.

\section{Implications for Practice}

While teachers spend a dedicated number of required (as well as often voluntary) hours every year in district and school-level PD, such PD is commonly viewed as ineffective, often due to the lack of evidence of greater teaching effectiveness (e.g., Hiebert et al., 2005). With teachers overwhelmingly viewing PD negatively and as an addition to their overflowing plate of responsibilities, the likelihood that traditional PD will have a positive, meaningful, and lasting impact on teacher professional practice is small.

PrimeD offers a structured framework as a map to systemically shift how PD programs are designed and implemented in ways that reposition teachers as leaders rather than mere participants. First, teachers themselves are engaged as active stakeholders, rather than only recipients, of the PD program. They participate in making decisions about the design and development (Phase I) as well as the implementation (Phase II) of the PD program. This change alone can address many pitfalls associated with traditional PD including applicability to classroom practice, based on teachers' needs, and teacher buy-in. Second, PrimeD provides a tool for all stakeholders (including PD providers, teachers, administrators, evaluators, etc.) to examine the PD program through an objective lens. Such objectivity allows for tough conversations to remain focused on the PD program itself and identifying possible solutions to challenges, rather than turning to unproductive conversations that might feel personal and uncomfortable. Third, PrimeD provides a coherent structure to support teachers to systematically implement strategies learned in whole group engagement PD sessions in their regular classroom instruction (through PDSA cycles). This feature is indispensable as it is a seamless component of the PD program, rather than an add-on or something extra teachers must do. Through employing a PD model in which teachers are empowered to be leaders and researchers in their own classroom, we have witnessed a renewed sense of agency that can be forceful and effective.

\section{Implications for PD Providers}

This study has important implications for PD providers (including designers, facilitators, evaluators, and researchers). First, PD providers are often assigned to develop a PD program because they are in a leadership or administrative position or because they have content or pedagogical expertise. Regardless of experience and expertise level, planning a comprehensive PD program that adheres to the effective elements of PD can be daunting, challenging, and stressful. Through this case study and our broader work, we have found that PrimeD provides a useful and much-needed structure for embarking on this complex task. PrimeD can be characterized as a roadmap that directs PD providers on where to start, what components to consider, what needs to be done, 
and how different components iteratively work together. PrimeD serves as a surface-level checklist as well as a deeper structure to guide rich considerations, tough conversations, and guidance on decisions to be made (Saderholm et al., 2017).

Second, because PrimeD synthesizes literature into a comprehensive framework and has been refined through a series of validation efforts, it can serve as a one-stop shop for all phases of a PD program (Rakes et al., 2017). For example, the elements of effective PD in Phase II compile recommendations from a wide array of literature such as Desimone (2009), Garet et al. (2001), Guskey (2000), Loucks-Horsely et al. (2010), Sztajn (2011), and Timperley (2011). PrimeD arms PD providers with a user-friendly way to justify and back their PD program decisions, needs, and requests to leadership in their school and district - which are unique to each individual context.

\section{Conclusions}

The findings from this single case study indicate that one key benefit of using PrimeD was the way in which it helped facilitate a collaborative and reflective dialogue among key investigators - a leadership team, community stakeholders, an external evaluation team, and STEAM instructional coaches and teacher participants. PrimeD inspired us to approach planning, implementing, evaluating, and researching PD in an entirely new way; one that guided us to be much more explicit and intentional in making decisions and addressing issues and roadblocks. While other high-quality PD models exist (such as Desimone, 2009; LoucksHorsley et al., 2010), the PrimeD framework is unique in that it focuses on all four phases of a PD program in extensive detail, and how those phases interact and inform each other. It incorporates a synthesis of literature on effective PD structured into a framework that can be systemically enacted. Using PrimeD provided a useful scaffold that centralized and synthesized the extant research on effective PD and provided a structure to effectively engage our partners and stakeholders. PrimeD helped us negotiate many challenges of managing a complex project while ensuring we considered the important components of $\mathrm{PD}$, made intentional decisions, collaborated meaningfully with participants and other stakeholders throughout this journey, and reflected continuously on how to best meet the needs of the teachers and their students - all while keeping focus on our challenge space (as in Bryk, Gomez, \& Grunow, 2010).

In essence, we came to realize PrimeD served as map that can be used to guide the design and implementation of a PD program and also to frame the evaluation of and the research on our PD program. As a map, PrimeD is complex, detailed, and expansive. We found that a single PD program, even a multiyear one such as ours, will not necessarily include every possible component shown in the map. Regardless, it was appropriate and important to consider all of the components so whatever was not included was done so intentionally. PrimeD helped us ensure all pieces of our PD program were aligned with one another so that, in sum, teachers received a well-designed, complete experience, and we were left knowing what worked well and what needed improvement (the evaluation component) as well as how and why certain components produced the associated outcomes (the research component).

Ultimately, teachers and their students receive a better product when PD is guided by a framework such as PrimeD. A PrimeD PD is not an isolated one-way conversation with teachers on how to teach their students, but rather, a non-hierarchical discussion among colleagues (i.e., teachers as partners rather than recipients) about the craft of teaching and the engagement of students in learning. PrimeD is built on the premise that effective long-term PD treats schooling as a shared responsibility among teachers, schools, and community stakeholders. A PrimeD PD goes beyond developing teacher knowledge or classroom practice to include opportunities for teacher leadership and collaboration. These collaborations engage teachers in actively contributing to the development of a common vision for teaching, evaluating the PD program and its activities, and assuming leadership roles in research in their classrooms. 
Enacting PrimeD was a drastic shift from traditional PD programs in this single case study. We learned daily how the framework itself could evolve and be modified to meet particular challenges. We encourage others to incorporate PrimeD as outlined here as a structure to guide the work of current and future PD programs. Using explicit PD models that incorporate research-based practices as outlined in PrimeD can lead to meaningful impact on the nature of PD and increase the probability of transforming teacher practice, increasing student learning, and contributing to the knowledge base on PD.

\section{References}

Bailey, C. (2016). An artist's argument for STEAM education. Education Digest, 81, 21-23.

Buck, G., Cook, K., Quigley, C., Eastwood, J., \& Lucas, Y. (2009). Profiles of urban, low SES, African American girls' attitudes toward science: A sequential explanatory mixed-methods study. Journal of Mixed Methods Research, 3, 386-410.

Borko, H. (2004). Professional development and teacher learning: Mapping the terrain. Educational Researcher, 33, 3-15.

Borko, H., Jacobs, J., Koellner, K., \& Swackhamer, L. E. (2015). Mathematics professional development: Improving teaching using the problem-solving cycle and leadership preparation models. New York, NY: Teacher's College Press (copublished with NCTM)

Bryk A. S., Gomez L. M., \& Grunow, A. (2010). Getting ideas into action: Building networked improvement communities in education. Stanford, CA: Carnegie Foundation for the Advancement of Teaching. Retrieved from http://cdn.carnegiefoundation.org/wp-content/uploads/2014/09/bryk-gomez building-nics-education.pdf

Chyung, S. Y. (2015). Foundational concepts for conducting program evaluations. Performance Improvement Quarterly, 27, 77-96. doi: 10.1002/piq.21181

Cohen, D. K., \& Hill, H. C. (2000). Instructional policy and classroom performance: The mathematics reform in California. Teachers College Record, 102(2), 294-343. doi: 10.1111/0161-4681.00057.

Cook, P. R. (2016). Adding art to STEM. Communications of the ACM, 59, 8-9. doi: 10.1145/2967972

Creswell, J. W., \& Miller, D. L. (2000). Determining validity in qualitative inquiry. Theory into Practice, 39, 124130.

Creswell, J. W. (2009). Research Design: Qualitative, Quantitative, and Mixed Methods Approaches. (3rd ed.). Thousand Oaks, CA: SAGE Publications, Inc.

Czerniak, C. M. (2007). Interdisciplinary science teaching. In S. K. Abell \& N. G. Lederman (Eds.), Handbook of Research on Science Education (pp. 537-560). Mahwah, NJ: Lawrence Erlbaum Associates.

Darling-Hammond, L. (1997). The right to learn: A blueprint for creating schools that work. San Francisco: Jossey-Bass.

Darling-Hammond, L. \& Richardson, N. (2009). Research review/teacher learning: What matters? Educational Leadership, 66(5), 46-53.

Desimone, L. M. (2009). Improving impact studies of teachers' professional development: toward better conceptualizations and measures. Educational Researcher, 38, 181-199.

Garet, M. S., Porter, A. C., Desimone, L., Birman, B. F., \& Yoon, K. S. (2001). What makes professional development effective? Results from a national sample of teachers. American Educational Research Journal, 38, 915-945.

Greeno, J. G., Collins, A. M., \& Resnick, L. B. (1996). Cognition and learning. In D. Berliner \& R. Calfee (Eds.), Handbook of educational psychology (pp. 15-46). New York, NY: Macmillan.

Guskey, T. R. (2000). Evaluating professional development. Thousand Oaks, CA: Sage. 
Hiebert, J. and Stigler, J. W. (2000). A proposal for improving classroom teaching: Lessons from the TIMSS video study. Elementary School Journal, 101, 3-20.

Hiebert, J., Stigler, J. W., Jacobs, J. K., Givvin, K. B., Garnier, H., Smith, M.,..., Gallimore, R. (2005). Mathematics teaching in the United States today (and tomorrow): Results from the TIMSS 1999 video study. Educational Evaluation and Policy Analysis, 27, 111-132.

Hom, E. J. (2014, February 11). What is STEM education? [website]. http://www.livescience.com/43296-whatis-stem-education.html

Horizon Research. (2000). Local systemic change through teacher enhancement professional development observation protocol. Retrieved from http://www.horizon-research.com/instruments/lsc/pdop.php

Jones, K., \& O'Brien, J. (2014). Introduction: Professional development in teacher education: European perspectives. In K. Jones \& J. O’Brien (Eds.), European perspectives on professional development in teacher education (pp. 1-6). New York, NY: Routledge.

Kennedy, M. M. (1998). Form and substance in in-service teacher education (Research Monograph No. 13). Arlington, VA: National Science Foundation.

Lave, J., \& Wenger, E. (1991). Situated learning: Legitimate peripheral participation. Cambridge, England: Cambridge University Press.

Liberman, A. (Ed.). (1996). Practices that support teacher development: Transforming conceptions of professional learning. In M. W. McLaughlin \& I. Oberman (Eds.), Teacher learning: New Policies, new practices (pp. 185-201). New York: Teachers College Press.

Lincoln, Y. S., \& Guba, E. G. (1985). Naturalistic inquiry. Newbury Park, CA: Sage Publications.

Loucks-Horsley, S., Stiles, E., Mundry, S., Love, N., \& Hewson, P. (2010). Designing professional development for teachers of science and mathematics. (3rd ed.). Thousand Oaks, CA: Corwin.

Martin, W. G., \& Gobstein, H., 2015. Generating a networked improvement community to improve secondary mathematics teacher preparation: network leadership, organization, and operation. Journal of Teacher Education, 66, 482-493. doi:10.1177/0022487115602312.

McAleer, S. D. (2008). Professional growth through mentoring: A study of experienced mathematics teachers participating in a content-based online mentoring and induction program. Dissertation Abstracts International-A, 69(08). (UMI No. 3319930)

National Governors Association Center for Best Practices \& Council of Chief State School Officers. (2010). Common core state standards: Mathematics. Washington, DC: National Governors Association and Author. Retrieved from http://www.corestandards.org/Math/

National Institute for Excellence in Teaching. (2014). Developing teacher leadership in Iowa: Saydel and Central Decatur Schools. Los Angeles, CA: Author. Retrieved from http://www.niet.org/assets/Publications/ niet-teacher-leadership-iowa.pdf?processed $=1$

NGSS Lead States. (2013). Next generation science standards: For states, by states. Washington, DC: The National Academies Press. Retrieved from http://www.nap.edu/catalog/18290/next-generation-sciencestandards-for-states-by-states

Patton, M. Q. (2002). Qualitative research and evaluation methods (3rd ed.). Thousand Oaks, CA: Sage.

Penuel, W. R., Fishman, B. J., Yamaguchi, R., \& Gallagher, L. P. (2007). What makes professional development effective? Strategies that foster curriculum implementation. American Educational Research Journal, 44, 921-958.

Peppler, K. (2013). STEAM-powered computing education: Using e-textiles to integrate the arts and STEM. Computer, 46, 38-43. doi: 10.1109/MC.2013.257

Philippou, S., Papademetri-Kachrimani, C., \& Louca, L. (2015). 'The exchange of ideas was mutual, I have to say': Negotiating researcher and teacher 'roles' in an early years educators' professional development 
programme on inquiry-based mathematics and science learning. Professional Development in Education, $41,382-400$.

Putnam, R. T., \& Borko, H. (2000). What do new views of knowledge and thinking have to say about research on teacher learning? Educational Researcher, 29, 4-15.

Rakes, C. R., Bush, S. B., Ronau, R. N., Mohr-Schroeder, M., \& Saderholm, J. (2017). Making teacher PD effective using the PrimeD framework. New England Mathematics Journal, XLX, 52-62.

Sabah, S. A., Fayez, M., Alshamrani, S. M., \& Mansour, N. (2014). Continuing professional development (CPD) provision for science and mathematics teachers in Saudi Arabia: perceptions and experiences of CPD providers. Journal of Baltic Science Education, 13, 91-104.

Saderholm, J., Ronau, R. N., Rakes, C. R., Bush, S. B., \& Mohr-Schroeder, M. (2017). The critical role of a wellarticulated conceptual framework to guide professional development: An evaluation of a state-wide two-week program for mathematics and science teachers. Professional Development in Education, 43, 789-818. doi: 10.1080/19415257.2016.1251485

Shadish, W. R., Cook, T. D., \& Campbell, D. T. (2002). Experimental and quasi-experimental design. Boston; New York: Houghton Mifflin Company.

Smith, C. E., \& Paré, J. N. (2016). Exploring Klein bottles through pottery: A STEAM investigation. The Mathematics Teacher, 110, 208-214.

Steyn, G.M., 2015. Die praktyk van Wiskunde-onderwysersamewerking soos gefundeer in die leergemeenskapsraamwerk en die uitnodigende onderwysbenadering [The practice of mathematics teacher collaboration as grounded in the learning community framework and the invitational education approach]. Tydskrif vir Geesteswetenskappe, 55, 694-711.

Sztajn, P. (2011). Research commentary: Standards for reporting mathematics professional development in research studies. Journal for Research in Mathematics Education. 42, 220-236.

Timperley, H. S. (2011). Realizing the power of professional learning. Maidenhead, ENG: Open University Press.

U.S. Department of Education. (2015). Science, technology, engineering and math: Education for global leadership. Washington, DC: Author. https://www.ed.gov/stem

Yin, R. K. (2017). Case study research and applications: Design and methods. (6th ed.). Thousand Oaks, CA: Sage. 